\title{
A Review on the Possibility for Nitriding of Aluminium Alloys
}

\author{
Siyana Vankova Zabunova \\ Technical University of Varna, Department of Material Science and Technology, 9010, 1 Studentska street, Varna, Bulgaria \\ Corresponding author contact: s.zabunova@tu-varna.bg
}

\begin{abstract}
The present paper provides a brief overview of the possibilities for nitriding the surface of Al-alloys. This treatment is still attracting scientific attention, not only as a means to increase the industrial life of materials but also as a way to comply with the current ecological requirements. On the whole, the purpose of such a process is to improve the mechanical properties like surface hardness and wear resistance of the Al-alloys, especially in automotive industry where "lightening" the whole construction is of great importance for reducing the fuel consumption. The paper, further, sets out to examine the influence of the technological parameters of this thermo chemical treatment on the thickness of the formed nitride layer and on the mechanical properties on one hand and the naturally formed oxide on the surface of the Al-alloys on the other hand. Drawn, in the end, are some conclusions about the potential benefits of nitriding and expressed is the specific need for its thorough research in the future.
\end{abstract}

Keywords: nitriding, aluminium nitride, surface treatment

\section{$1 \quad$ Introduction}

It is usually accepted aluminum ( $\mathrm{Al})$ and aluminium alloys (Al-alloys) to be called "light materials" in nowadays, because of their low weight, (Vargel, 2020). Aluminium is in the group of the light metals together with magnesium and beryllium. Its density is $2.7 \mathrm{~g} / \mathrm{cm}^{3}$ and the melting temperature is $660^{\circ} \mathrm{C}$. The reasons for the wide usage of this material in our daily life is connected with its physical properties and possibilities for production and easy treatment. Looking back in time it can be seen that aluminium has become one of the most appropriate analogue of steel in many details, machine parts and structures, especially in buildings, (Müller, 2011). The automotive industry is the most important consumer of Al-alloys. They are used in parts like engine pistons, cylinder blocks, etc. Traditionally these details are castings from highly alloyed Al-alloys and have good corrosion resistance and specific strength. Other applications that can be found about these materials are in the other transportation sectors like railroad, marine, aerospace, defence industries, production of wheels of armoured vehicles, massive brake gears, etc., (Zolotorevsky, 2007).

The existing constant requirement for decreasing emissions of carbon dioxide and other polluting gaseous emissions has brought to the need of reducing the fuel consumption of cars. One of the ways to ensure that is to "lightened" the whole car construction. In the automotive industry the Al-Si alloys are widely used. A 30-40 \% percent of all products produced from $\mathrm{Al}$ are castings and $75-80 \%$ of castings in USA, Western Europe and Japan are from recycled Al scrap. In the last 20 years due to the development and improvement of casting technologies high-quality castings are produced. Their production cost and properties are good enough in compare with the wrought products. The global production of aluminium has been increased two times for the last 15 years, (Lumley, 2018). This means that this material has found its place in the industry sectors, it is well accepted from the consumers and satisfy the needs and the requirements about his qualities. The good corrosion resistance, toughness, low weight are the advantages of the $\mathrm{Al}$ and its alloys as mentioned above. Surface hardness and wear resistance of not enough high level on the other side give limitation for its application in different machine parts and for that reason there is a constant looking for a methods and technical decisions to improve the mechanical properties and also to increase the industrial life of the material. Al-alloys with 
silicon content (Al-Si alloys), called also "silumins" are very often used in the production of automotive parts, (ASM int. handbook,1993). Al-Si system has eutectic at $577^{\circ} \mathrm{C}$ and $12,5 \mathrm{wt} . \%$ of Si, (Fig.1). The process of cooling the structure under formation is presented by primary $\mathrm{Al}$ dendrites surrounded by eutectic phase. Hypoeutectic alloys, alloyed with $\mathrm{Mg}(0,3 \%)$ are usually used in industry. Applied, practically, is a modification with $\mathrm{Na}$ (up to 0,1$)$ and $\mathrm{Sr}(0,03 \%)$.

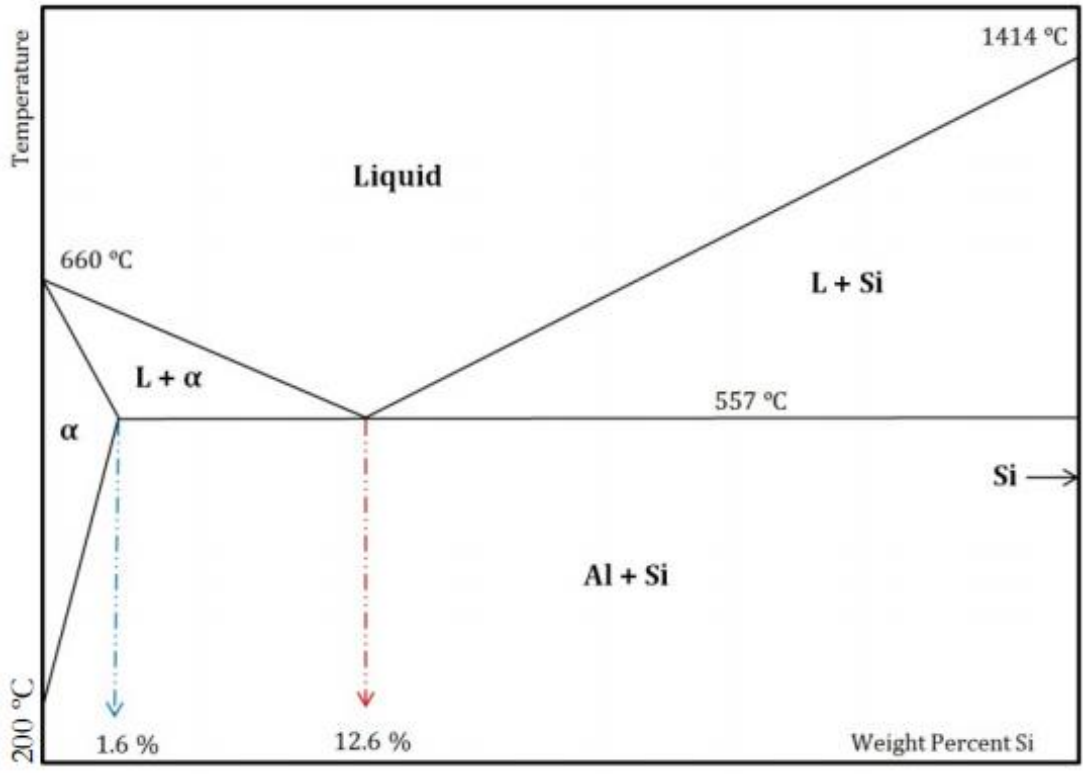

Fig. 1. Al-Si eutectic phase diagram (Retrieved from https://chemistry.stackexchange.com/questions/111790/eutectic-phase-diagram-of-al-si-analysis)

It should be noted, though, that there is a dependency between the mechanical properties of $\mathrm{Al}-\mathrm{Si}$ alloys and their modification. The structure of the $\mathrm{Si}$ in the eutectic phase plays a key role for the final properties of the alloy. In the industrial application Al-Si castings contain impurities and solidify at relatively low cooling rates. And as reports further state, the modification changes the structure from coarse into a fine-fibrous. The size and form of the $\mathrm{Si}$ particles are reduced and this refinement, in turn, affects their mechanical characteristics, (Rossi, 2015). The modification of structure, that practically means spheroidization of the initially shaped particles during casting, improves mechanical properties, especially ductility of Al-Si alloys. This method has become a standard in the production of engine pistons, (Zeren, 2006). Illustrated in Fig.2 are the microstructures of the pure material and those of the generated modification. 


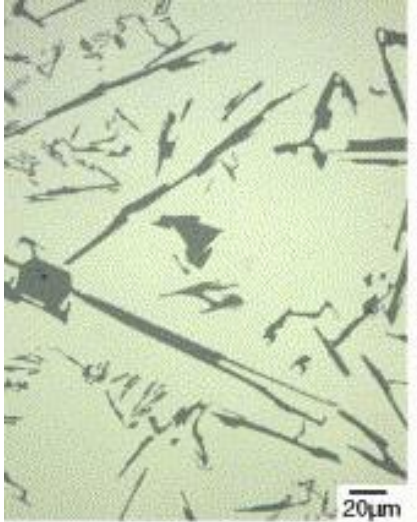

(a)

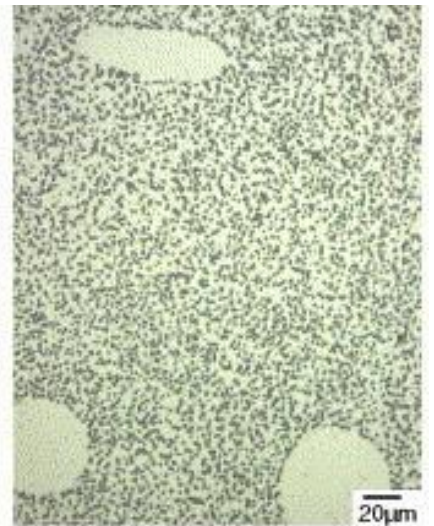

(b)

Fig. 2. Al-Si alloy microstructures: a) no-modified; b) modified with $\mathrm{Sr}$ (Dahle et al., 2005)

Another way of improving the properties of aluminium casting alloys is to create a surface layer with increased hardness through thermo-chemical treatment. This kind of surface aluminium nitride (AlN) hard film modification on the top of the details is likely to increase their lifetime.

\section{$2 \quad$ Nitriding Technology}

$\mathrm{Al}$ alloys are an ideal selection for some automotive parts from ecological point of thinking because it can reduce the total weight of the cars, bringing about a decrease in the fuel consumption and thus, minimizing the respective environmental burden and gas emissions. To that effect, there is still a need to explore and seek for a solution as to the low hardness and wear resistance which both are the main limitations connected with the aluminium application. The naturally formed alumina coating, a thick oxide layer of $\mathrm{Al}_{2} \mathrm{O}_{3}$ is not wear resistant due to its high friction coefficient. On the other hand, the advantages of the AlN are its hardness $(1400 \mathrm{HV})$ and thermal conductivity $(319 \mathrm{~W} / \mathrm{mK})$, measured at room temperature. AlN layer can be formed on top of the details surface by different methods like ion implantation, plasma immerse ion implantation (PII), ball milling, plasma and gas nitriding. On the other side it is important to preserve the small size and spherical form of primary eutectic silicon and not to decrease its machinability or tensile strength, (Visuttipitukul et al., 2003).

Aluminium as a metal forming a nitride is used like a major alloying element ( $\mathrm{Al}$ up to 1,2\%) in steels that has to be nitrided. There is an important difference between the behaviour of ferrous alloys (Fe-alloys) when they are subjected to nitriding and non -ferrous ones. The solubility of nitrogen in the basic metal is definitive in the process, the liquidus and solidus temperatures and affinity of the basic metal to the oxygen. Nitrogen is virtually insoluble in Al-alloys and for that reason a compound layer is formed without a precipitation -hardened layer (no diffusion zone) as it is found in Fe-alloys (Fig.3). 


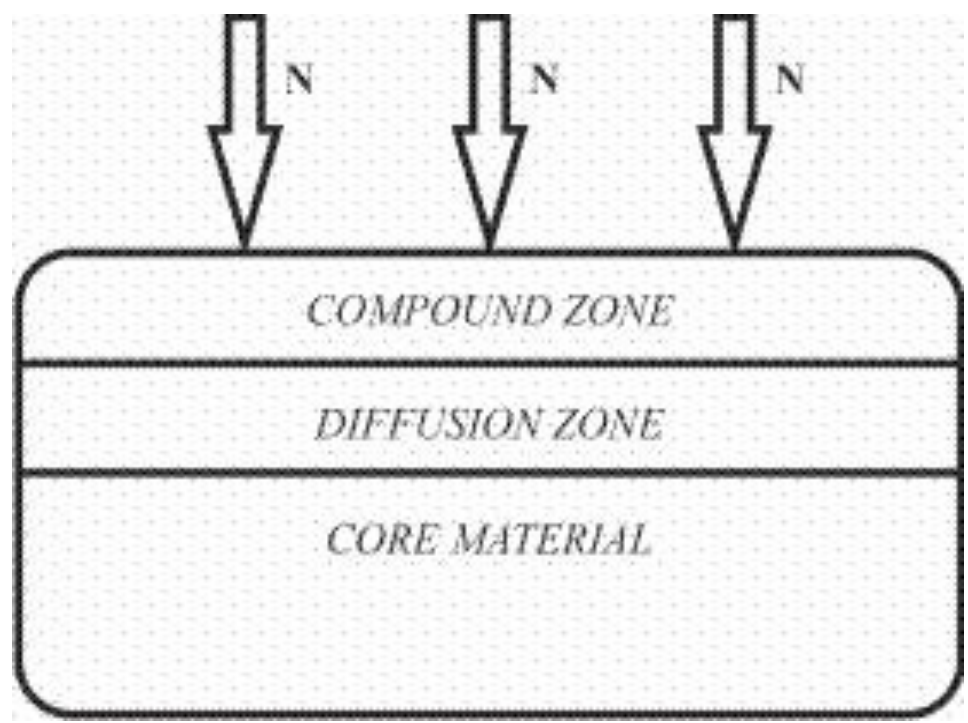

Fig. 3. Formation of surface layers during nitriding process

Nitriding temperatures are often above the temperatures used for annealing Al-alloys and logically, have a strong impact on the matrix structure. Besides, taken into consideration should also be the possible partial melting of the surface. Another disadvantage is the passivation of the aluminium surface. Although the process of forming a natural oxide layer is more complex on Al-alloys than pure aluminium, cleaning pretreatment of the surface prior to nitridation would be quite appropriate. The extensive literature on the subject under consideration argues that the oxygen pressure, temperature and the condition of metal surface and also the alloying elements have influence on the thickness and structure of the alumina oxide. The concentration of the alloying element on the oxide film is not the same as that in the matrix beneath. Regarding $\mathrm{Al}-\mathrm{Mg}$ alloys, the oxide film on the surface is presented by $\mathrm{MgO}$ and $\mathrm{Al}_{2} \mathrm{O}_{3}$ or $\mathrm{Al}_{2} \mathrm{MgO}_{4}$ and a porous film of $\mathrm{MgO}$. The reason is the higher diffusion coefficient of $\mathrm{Mg}$ than the $\mathrm{Al}$ and the reduction reaction above temperature of $300^{\circ} \mathrm{C}$. In addition, the elements $\mathrm{Cu}$ and $\mathrm{Zn}$ cause a decrease in the density of the alumina oxide crystals, and this is more intensive in higher temperatures (around $475^{\circ} \mathrm{C}$ ), (Vargel, 2020). Reference should be made to the role of the alloying elements in the nitridation process and the groups of microstructure casting alloys that might be submitted to nitridation for improvement of their properties. Fe as is widely known reacts strongly with nitrogen. The main principle used in nitridation of Fe alloys connected with the solubility of nitrogen in iron cannot be applied because in aluminium alloys iron is used as an additive rather than as an alloying element. The solubility of iron in aluminium alloys is up to $0,05 \%$. If the Fe content is higher, then the intermetal phases that are formed with the Al-Si alloys have an adverse impact on their mechanical properties. The alloying elements and additives that are used in Al-alloys are presented in Table 1. Some of them react with aluminium in forming phases from eutectic reaction, others make solid peritectic solutions and chemical compositions. The role of additives and alloying elements is still in the course of investigation in order for new Al- based materials to be uncovered. 
Table 1. Concentration of the Alloying elements and additives in Al alloys, (Zolotorevsky et al., 2007)

\begin{tabular}{|c|c|c|c|c|}
\hline $\begin{array}{r}\text { Alloying el- } \\
\text { ement/Additive }\end{array}$ & $\begin{array}{c}\text { Limit of } \\
\text { Solubility at } \\
\text { Te/p }{ }^{\circ} \mathrm{C}, \%\end{array}$ & $\begin{array}{c}\text { Concentration in } \\
\mathrm{E} / \mathrm{P} \\
\text { Reaction, \% }\end{array}$ & $\begin{array}{c}\mathrm{T}^{0} \mathrm{C} \\
\mathrm{E} / \mathrm{P}\end{array}$ & Phases in equilibrium \\
\hline $\mathrm{Cu}$ & 5,7 & 33,2 & 547 & $\mathrm{CuAl}_{2}(52 \% \mathrm{Cu})$ \\
$\mathrm{Mg}$ & 17,4 & 35 & 450 & $\mathrm{Mg}_{5} \mathrm{Al}_{8}(35 \% \mathrm{Mg})$ \\
$\mathrm{Zn}$ & 82 & 94,9 & 382 & $(\mathrm{Zn})(99 \% \mathrm{Zn})$ \\
$\mathrm{Si}$ & 1,65 & 12 & 577 & $(\mathrm{Si})(99,5 \% \mathrm{Si})$ \\
$\mathrm{Fe}$ & 0,05 & 1,8 & 655 & $\mathrm{FeAl}_{3}(40 \% \mathrm{Fe})$ \\
$\mathrm{Ni}$ & 0,04 & 6,0 & 640 & $\mathrm{NiAl}_{3}(42 \% \mathrm{Ni})$ \\
$\mathrm{Mn}$ & 1,8 & 1,9 & 658 & $\mathrm{MnAl}_{6}(25 \% \mathrm{Mn})$ \\
$\mathrm{Ti}$ & 1,3 & 0,12 & $661(\mathrm{p})$ & $\mathrm{TiAl}_{3}(37 \% \mathrm{Ti})$ \\
$\mathrm{Cr}$ & 0,8 & 0,4 & $661(\mathrm{p})$ & $\mathrm{CrAl}_{7}(22 \% \mathrm{Cr})$ \\
& & & & \\
\hline
\end{tabular}

- $\quad \mathrm{E} / \mathrm{P}-$ Eutectic/Peritectic

An experimental study by $\mathrm{x}$-ray photoelectron spectroscopy using synchrotron radiation (SP-XPS) on $\mathrm{Al}$ alloy powders with $\mathrm{Mg}$ concentration of around $0,63 \%$ explained the reduction role of $\mathrm{Mg}$ upon the process of natural oxidation of the material surface. The findings of the research study hereto proposed confirm that heating at temperatures above $499.85^{\circ} \mathrm{C}$ causes disappearance of the oxide film because of the intense diffusion of $\mathrm{Mg}$ atoms from the "core material" to the surface. After this reduction reaction of the $\mathrm{Mg}$ atoms, the "naked" aluminium surface has been nitrided. The reduction reaction (Kimura et al., 1997) is the following

$$
\begin{gathered}
3 \mathrm{Mg}+4 \mathrm{Al}_{2} \mathrm{O}=3 \mathrm{~A}_{2} \mathrm{MgO}_{4}+2 \mathrm{Al} \\
3 \mathrm{Mg}+\mathrm{Al}_{2} \mathrm{O}_{3}=3 \mathrm{MgO}+2 \mathrm{Al}
\end{gathered}
$$

The Mg vaporizes from the material top surface, and the nitride aluminium surface is the concrete evidence that points to the breakage of the oxide film, (Kimura et al., 1997). Species without Mg content, that were also used in the experimental study, have been subjected to the same treatment conditions but formation of the nitride layer has not been detected. The reaction between aluminium oxide and $\mathrm{Mg}$ on the surface of the alloys in the process of heating has not been fully analyzed by the overwhelming majority of the researchers. The production of composite materials of AlN is an object of interest where the interaction of nitrogen with the aluminium alloy melt is important to be investigated. (Po-Chen Chen et al., 2009).

Another research on the specifics of sintering process of $\mathrm{Al}$ powders, where the $\mathrm{Al}_{2} \mathrm{O}_{3}$ on the surface of powder particles is important disadvantage, also reconfirmed the reductional role of $\mathrm{Mg}$ even in a minimal quantity on the oxidized surface of alumina powder material and its indirect influence on the nitriding process, (Schubert et al., 2005). Nitrogen is the most suitable gas for sintering aluminium powders because of its enormous role for the shrinkage and respectively receiving the compact material with the required mechanical qualities. The sintering temperature $\left(620^{\circ} \mathrm{C}, 2\right.$ hours $)$ is very close to the melting point of $\mathrm{Al}$. It is proved that this is an exothermal process with a presence of a liquid phase. The result is a new microstructure, presented by aluminium oxy-nitrides and aluminium nitride with a different shape. It can be said that during the sintering process of $\mathrm{Al}$ a nitriding process is also 
taking place, (Pieczonka et al., 2016). Destruction, or maybe it is more appropriate to be referred as transformation, of the alumina oxide with amorphous structure occurs when an Al based powder material is sintered in an atmosphere of pure nitrogen because of exothermic interactions. The appearance of internal thermal tensile stresses is responsible for microcracks in the oxide film. The process of volume diffusion and differences in quantity of a solid and a liquid phase are further factors for ensuring the direct contact of aluminium and nitrogen. The distribution of the phases in the sintered material is a surface that is re-oxidized and porous, sintered Al layer and nitrided core structure, (Pieczonka, 2017). The nitriding is proved to be happen mostly in the inner side, not in the surface. The evidence for that is the calculated quantity of oxygen/nitrogen in the surface, respectively in the matrix. The investigation of sintering powder Al materials are attracting scientific interest because of the various applications, including automobile parts.

Thermochemical treatment as a classical possibility for surface engineering has its place in automotive industry for finding solutions about the reduction of wear, friction and corrosion. The applications could be found in nitriding or nitrocarburising (with oxidation) of piston rings, ball pivots, clutches, etc., (Vetter \& Barbezat , 2005). It appears that not only the coating technology but the thermochemical treatment as nitriding, combined with some after- treatment like coating deposition for example can lead to the same better effect on the working qualities of the automobile components, (Bewilogua et al., 2009).

Remarkable progress has been achieved in developing a technological process of plasma nitriding of aluminium alloys in the last two decades (Fig.4).

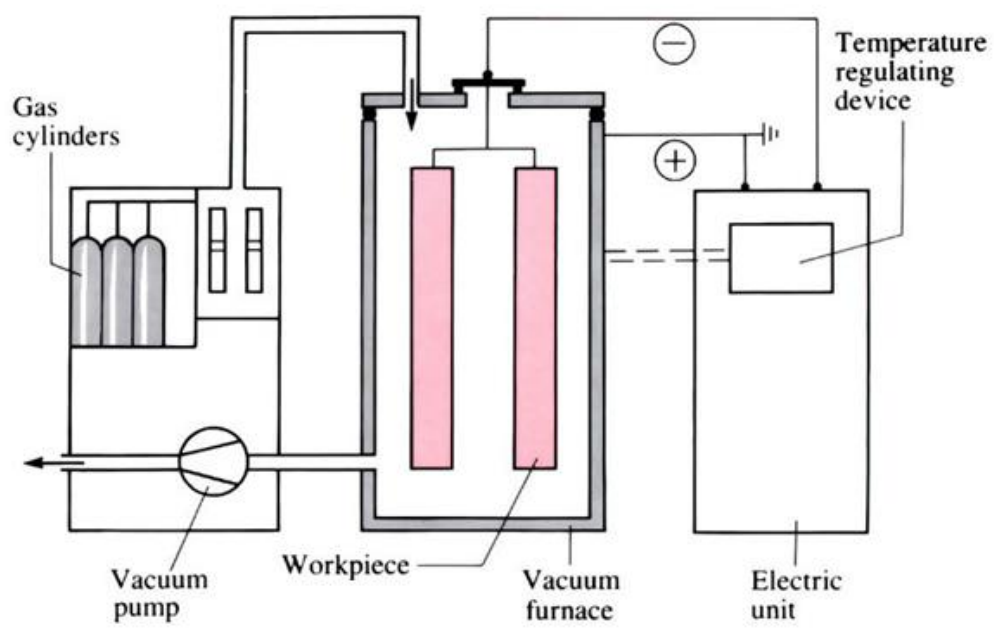

Fig. 4. Plasma nitriding installation scheme (Retrieved from https://www.open.edu/openlearn/science-mathstechnology/engineering-technology/manupedia/plasma-nitriding/carburising)

Reported in many scientific studies is the formation of AlN with particularly high hardness (up to $1500 \mathrm{HV}$ ). To achieve the primary purpose of improving the surface qualities in strict compliance with the industrial requirements is still in the stage of development and under further investigation. The possibility of the gas nitriding process to form ALN on Al-alloy has been tested and verified. The purpose of the investigation is to observe the emissivity of $\mathrm{AlN}$ and surface structure of $\mathrm{Al}$ and $\mathrm{Mg}$ powders. The species were nitrided at $499.85^{\circ} \mathrm{C}$ and at $549.85^{\circ} \mathrm{C}$ for $0-5$ hours, (Yoshida et al., 2015). The temperature range is connected with the above-mentioned reduction of natural oxide on the aluminium surface in the presence of $\mathrm{Mg}$. The result after nitriding process was a fine acicular AlN nodules with diameters of several micrometers. Accordingly, dark brown films were closely discerned. Another metal titan (Ti) as $\mathrm{Al}$ and $\mathrm{Mg}$ has affinity with oxygen as well but, what is more, it has a higher melting point, so the outcomes of some experimental work into the gas nitriding of titan alloys will be dis- 
cussed by analogical reasoning. Gas nitriding significantly increases roughness of alloyed titan materials because of the formation of titan nitrides and oxides on the surface. It is important to be noted that the hardness is very high only on the surface of the material, but the value become lower in the core material. (Zhecheva et al.,2006).

In a scientific research a surface of specimen of pure aluminium A7, with a chemical composition of $99,7 \% \mathrm{Al}, \mathrm{Fe}, \mathrm{Si}-$ up to $0,16 \%$, Ti- $0,02 \%, \mathrm{Cu}, \mathrm{Zn}$ up to $0,01 \%$, has been subjected to nitriding in plasma of non-self-sustained glow discharge with hollow cathode, (Krysina et al., 2017). The authors state that there is a principal possibility of nitriding an Al. Confirmation of the improved mechanical and tribological characteristics due to the formed ALN is received by X-ray diffraction analysis and transmission electron microscopy. Hardness increased around 4 times, wear resistance up to 40 times and the friction coefficient decreased from 0,6 to 0,2 in compare with initial specimen before the nitridation process. As a matter of fact, aluminium alloys that are generally accepted in the industry are those with a more complex structure alloyed with a variety of elements and additives. Their surface is quite different from the pure Al material. Alloying with $1 \% \mathrm{Ti}$ could be helpful for increasing the thickness of the Al layer. It was investigated in experimental research where the formed film on the aluminium powders with $1 \%$ Ti during plasma nitridation reached $3 \mu \mathrm{m}$. Coexistence of TiN with AlN assured that titanium has an effect on activation of AlN formation due to its high affinity to nitrogen (Visuttipitukul et al., 2003).

In other research it was reported the influence of one of the technological parameters of the DC pulsed plasma nitriding process while the other parameters were constant. Three different concentrations of the gas were used during the process and due consideration was given to their effect on the surface morphology, hardness, phases composition and corrosion performance. In the beginning prior to the nitriding process of specimens from $\mathrm{Al} 6061$, a cleaning (sputtering) stage was performed for 30 minutes at $350^{\circ} \mathrm{C}$ in $100 \%$ Ar. The constant technological parameters of the process were 4 hours continuance, pressure of 1,9 Torr and heating at temperature of $400^{\circ} \mathrm{C}$. The changing parameters were the concentration of nitrogen that vary from 50to $100 \%$. Samples were cooling down to room temperature after the treatment inside the processing chamber. Argon gas atmosphere was once more applied in order to prevent oxidation, (Zamarripa-Pina et al., 2013). The best results were observed in an atmosphere with $50 \%$ of nitrogen that is consistent with the increase in hardness (1,3 times) and at the same time is sufficient enough for preserving the structure from cracks and undesired modification. The purpose of this surface was achieved through a formed layer of AlN that has been hexagonal or cubic.

Al- Si casting alloys usually are not subjected to heat treatment. Si phase in eutectic do not change its volume during heating. If they have content above $0,5 \% \mathrm{Mg}$ as an additive, an age hardening or quenching are possible because of the secondary forming phase $\mathrm{Mg}_{2} \mathrm{Si}$. The heat treatment usually is applied for homogenizing the structure, fixing the form and size of the casting and relaxing the inner stresses. The chemical composition of typical casting near eutectic alloy with good machinability, high chemical resistance is presented in Table 2.

Table 2. Chemical Composition, wt \%, (Spies \& Dalke, 2016)

\begin{tabular}{|c|c|c|c|c|c|c|c|c|}
\hline Al Alloy & $\mathrm{Al}$ & $\mathrm{Si}$ & $\mathrm{Mg}$ & $\mathrm{Fe}$ & $\mathrm{Zn}$ & $\mathrm{Cu}$ & $\mathrm{Mn}$ & $\mathrm{Ti},(\mathrm{Ni})$ \\
\hline $360.0 \mathrm{AlSi} 10 \mathrm{Mg}$ & $\mathrm{bal}$ & $9.0-11.0$ & $0.2-0.45$ & 0.55 & 0.1 & 0.05 & 0.45 & 0.15 \\
\hline
\end{tabular}

This alloy is used for details with complicated geometry, thin walls, subjected to fatigue loading, (https://www.stenaaluminium.com, 2019). It was nitrided in temperature of $460^{\circ} \mathrm{C}$ and the time of nitriding $\mathrm{Al}$-alloys with $\mathrm{Mg}$ (up to $0.45 \%$ ) was carefully examined. The thickness of the nitride film was concluded to grow larger with the increase in time of nitriding. The same, though, cannot be concluded about the Al-Si alloys with magnesium lowest content (0.2\%) so there is an optimal content of $\mathrm{Mg}$ that is important for the nitridation and the growth of the nitride layer. For the hypoeutectic and eutec- 
tic alloys in silicon-rich areas the nitride formation was delayed. The nitriding caused a reduction in core hardness so to regenerate the substrate hardness, a subsequent solution treatment and ageing was suggested to be carried out after the nitriding process. (Spies \& Dalke 2016). Presented in Fig. 5 is the effect of heat treatment for Al-alloys, applied after nitriding which is proved to be possible and with no effect on the formed nitride layer.

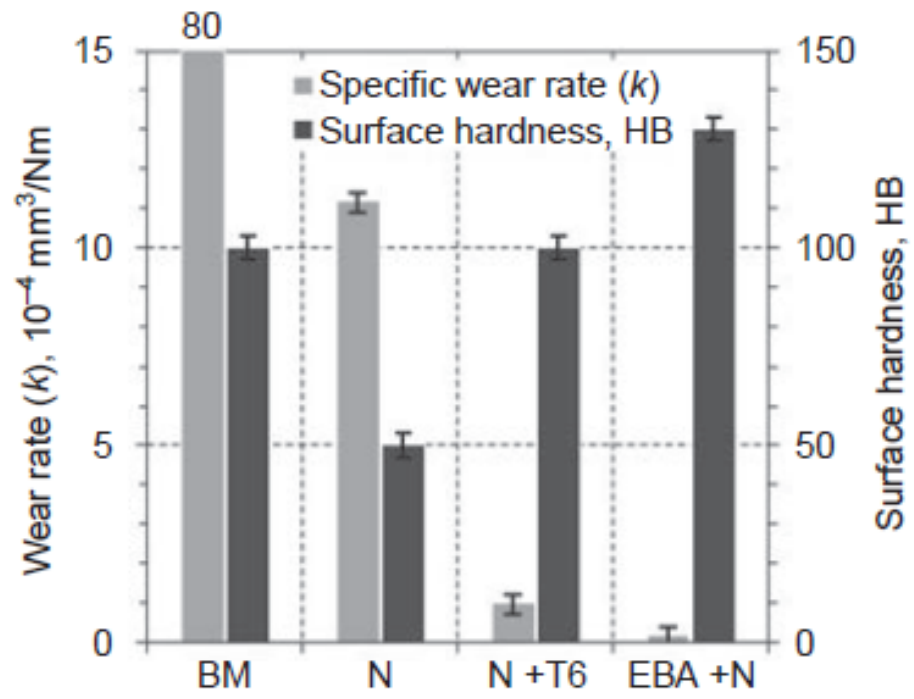

Fig. 5. Mechanical properties of spray formed Al-alloy after nitriding, nitriding and aging, electron beam alloying plus nitriding (Spies \& Dalke, 2016)

Good experimental results about hardness have been received after plasma nitriding on welded $\mathrm{Al}$ based materials. The purpose of applying this kind of after- treatment is to reinforce the welded structure, (Afriansyah et al., 2019). The microstructure is displayed below (Fig.6), followed by the increasing value of hardness in the Fig.7. The roughness and the dark zones of nitrides can be easily perceived.

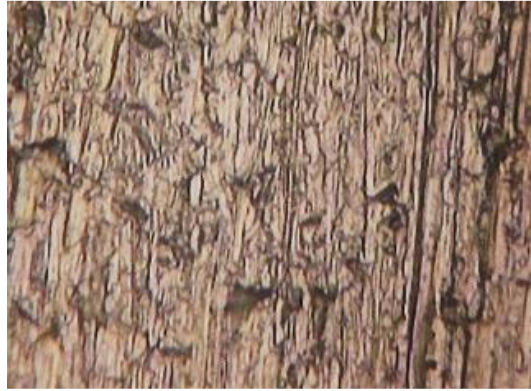

a)

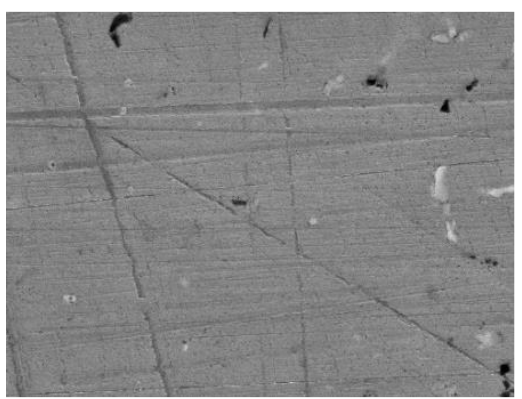

b)

Fig. 6. a) nitrided microstructure, optical microscope (400x); b) SEM micrograph of the same structure (8000x), (Afriansyah et al., 2019) 


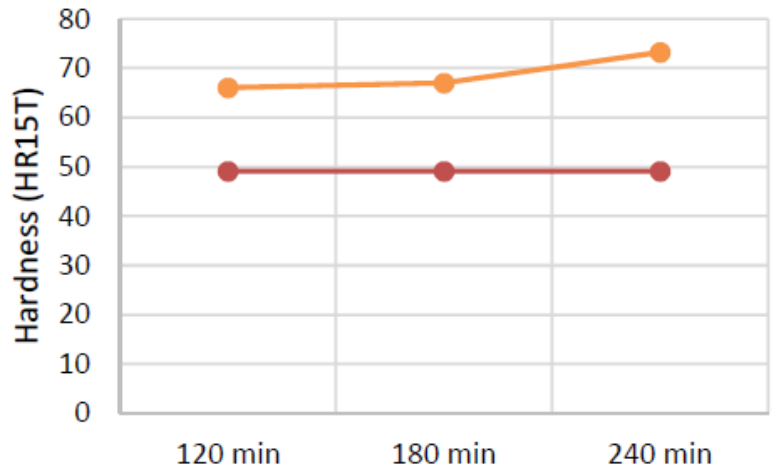

Fig. 7. Increasing values of hardness in the process of nitriding, (Afriansyah et al., 2019)

In the last 30 years, there has been a very successful research and investigation work in Bulgarian laboratories about the methods of thermo-chemical treatment, especially in the Technical university of Varna regarding gas nitrocarburising and carbonitriding technologies for improving the properties of Fe-alloyed powders. The influence of this technology upon the hardness of the surface and the structure of the powder matrix, (Mincheva \& Petrov, 2019) was extensively explored and thoroughly investigated. Additional studies were performed into the process of alloying the molten aluminium matrix with $\mathrm{Cu}$ powder using the capillary technique for receiving a composite material, (Spasova et al., 2019).

Plasma nitriding technology on Fe materials has been well researched and investigated in the existing scientific laboratory in Technical University of Sofia and implemented in more than 40 companies in Bulgaria and abroad, (TU-Sofia, Nil EFttom, Bulgaria,2021), (Ionitech Ltd, 2021).

Regarding the possibilities for gas nitriding, carbonitriding or nitrocarburizing of Al-alloys the alumina oxide has proved to be an obstacle for applying the advantages of these surface methods.

\section{Discussion}

Most reports about the formation of AlN through a nitridation process (Fig.8) and the achieved experimental results bring special prominence to the desired effect of this thermo-chemical treatment on the mechanical properties like surface hardness and wear resistance.

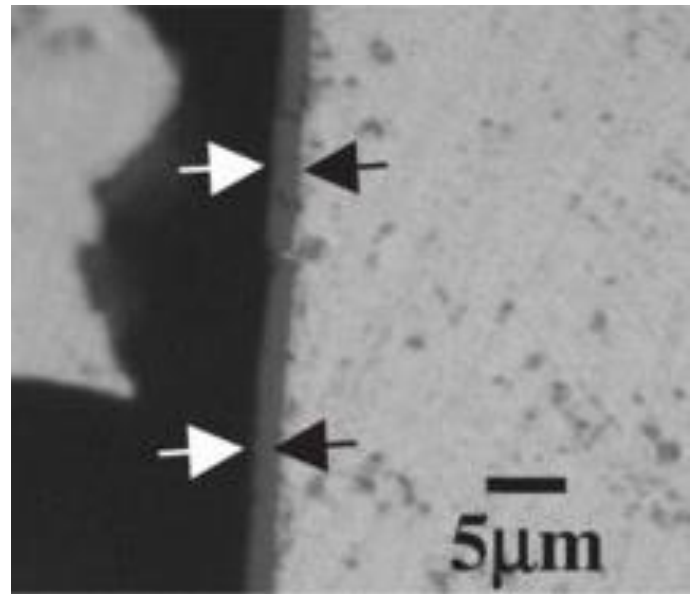

Fig. 8. Nitrided surface of specimen from aluminium casting material by SEM (Visuttipitukul et al., 2003) 
The advantage of plasma nitriding process is the presputtering stage that is conducted prior to nitridation. There is not enough research regarding the possibility of gas nitriding of aluminium alloys. Special mention has been made to the fundamental necessity of Mg. According to the technological parameters of nitridation, increasing the time of nitriding too much is not related to the higher thickness of the layer or with the refinement of structure. The same conclusion could be made for the concentration of nitrogen. These parameters have to be optimal in order to prevent microcracks in the process of cooling as a result of the different coefficient of thermo-expansion of the nitride layer and the aluminium matrix. The temperature of nitriding is a parameter connected with the melting point of chemical components of an alloy that has to be nitrided and it is also optimal for forming a nitride surface layer with enough thickness without any partial melting of the material. Because of the exothermic character of the reactions and the melting temperature of additives and alloying elements, there is likely to be a decrease in the temperature of melting. Nitriding temperatures are high (close to solidus temperature) for aluminium alloys in comparison with the nitriding temperatures for ferrous materials, and for that reason some changes would be observed in the initial properties of the aluminium matrix (the core structure). Subsequently, some solution treatment after the nitriding should be applied. Friction and wear resistance are strongly connected and influenced by the tribological characteristics of the surfaces of the machine parts where cracks occur.

\section{Conclusions}

The Plasma/ion nitriding technology and equipment can be successfully applied for Al-alloys that are not subjected to hardening heat treatment to obtain the AlN layer. There is, however, not enough research or investigation about the possibility for gas nitriding of aluminium alloys. Future experimental work is, therefore, needed for a deeper understanding of the formation of a structure of nitride layer on the aluminium matrix and especially into its roughness caused by the presence of oxides. Indeed, the process of nitriding as a surface technology has its place in automotive industry, which, in turn, gives reasonable grounds for further scientific investigation and studies into the thermo- chemical treatment of aluminium surface that will provide greater understanding of the material behavior and its potential application.

\section{References}

Afriansyah, A., Santjojo, D. J., \& Istiroyah. (2019). Hardness analysis for low-temperature plasma nitriding RF-DC of TIG welding joint Al 6061 sheets. In AIP Conference Proceedings (Vol. 2202, No. 1, p. 020050). AIP Publishing LLC.

Crossref

Bewilogua, K., Bräuer, G., Dietz, A., Gäbler, J., Goch, G., Karpuschewski, B., \& Szyszka, B. (2009). Surface technology for automotive engineering. CIRP annals, 58(2), 608-627. $\underline{\text { Crossref }}$

Spies, H. J., \& Dalke, A. (2016). Nitriding of Aluminum and its Alloys. Gas, 500, 930. Crossref

Dahle, A. K., Nogita, K., McDonald, S. D., Dinnis, C., \& Lu, L. (2005). Eutectic modification and microstructure development in Al-Si Alloys. Materials Science and Engineering: A, 413, 243- 
248.

Crossref

Davis, J. R. (1993). Aluminum and aluminum alloys. ASM international. Google Scholar

Kimura, A., Shibata, M., Kondoh, K., Takeda, Y., Katayama, M., Kanie, T., \& Takada, H. (1997). Reduction mechanism of surface oxide in aluminum alloy powders containing magnesium studied by x-ray photoelectron spectroscopy using synchrotron radiation. Applied physics letters, 70(26), 3615-3617.

Crossref

Krysina, O. V., Denisov, V. V., Ostroverkhov, E. V., \& Tolkachev, O. S. (2017). Nitriding of surface of technically pure aluminum in plasma of non-self-sustained glow discharge with hollow cathode. Uglov, V.V. (Ed.), Interaction of radiation with solids, Proceedings of 12 International Conference, (p. 483). Belarus Google Scholar

Lumley, R. (2018) Introduction: Aluminium the strategic material, Fundamentals of Aluminium Metallurgy, Recent Advances, ISBN: 978-0-08-102064-7 (online), ISBN: 978-0-08-102063-0 (print)

Google Scholar

Müller, U. (2011). Introduction to Structural Aluminium Design. ISBN 978-184995-007-7. Google Scholar

Mincheva, D. \& Petrov, P. (2019). Effect of applied chemical heat treatment on the structure and properties low - alloy Cr- containing iron powders, MATEC web conf., vol. 287. Crossref

Pieczonka, T., Kiebak B., Kazior J. (2016). Reactions and Microstructure Evolution During Sintering of High Purity Aluminium in Nitrogen. Powder Metallurgy World Congress and Exhibition, Lightweight MMCs. Google Scholar

Pieczonka, T. (2017). Disruption of an aluminina layer during sintering of aluminium in nitrogen, Arch. Metall. Mater. 62, 2B,987-992.

Crossref

Po- Chen Chen, Teng-Shih and Chin - Yie Wu. (2009). Thermally Formed Oxides on Al-2 and 3.5 mass $\% \mathrm{Mg}$ Alloy heated and held in different gases, J Material Transactions, 50(10), 2366 2372.

Crossref

Schubert, Th., Pieczonka T., Baunack S., Kieback B. (2005). The influence of the Atmosphere and impurities on the Sintering Behaviour of Aluminium. Proc. Euro PM 2005 Powder Metallurgy Congress and Exhibition, Prague, Czech Republic, Vol.1, 3-8 Google Scholar

Spasova, D., Radev R., Atanasov N., Yankova R. (2019) Investigation to obtain complex relief MMC with metal matrix $\mathrm{Al}$ and $\mathrm{Cu}$ reinforcement phase. Advances in Materials and processing Technologies 5 (4):1-7.

Crossref 
Vargel, C. (2020) Corrosion of Aluminium (Second ed.), ISBN: 978-0-08-099925-8

Vetter, J., Barbezat.J. (2005). Surface treatment selections for automotive applications. Surface and coatings technology 200, $1962-1968$.

Crossref

Visuttipitukul, P., Aizawa T., Kuwahara H. (2003). Advanced Plasma Nitriding for Aluminum and $\begin{array}{lllll}\text { Aluminum } & \text { Alloys. } & J & \text { Mat } & \text { Trans, }\end{array}$ $\underline{\text { Crossref }}$

Yoshida, M., Utsumi, N., Ichiki, R., Kong, J. H., \& Okumiya M. ( 2015). Surface Structure and Emissivity of Aluminum Nitride Films. Advanced Materials Research, 1110, 163-168. Crossref

Zamarripa-Pina, J. S., Hdz-Garcia, H. M., Díaz-Guillen, J. C., Aguilar-Martinez, J. A., GrandaGutierrez, E. E., \& Gonzalez, M. A. (2013). Increase in Hardness and Chloride Corrosion Resistance of 6061 Aluminum Alloy by Pulsed Plasma Nitriding, International Journal of Emerg. Tech and Adva. Engineer. 3(6) 348-353.

Google Scholar

Zeren, M. (2007). The effect of heat-treatment on aluminum-based piston alloys. Materials \& design, 28(9),

2511-2517.

Crossref

Zhecheva, A., Malinov S., Sha W. (2006). Titanium alloys after surface gas nitriding. Surface and Coatings Technology, 201(6), 2467-2474.

Crossref

Zolotorevsky, V., Belov N, Glazoff M. (2007). Casting Aluminum Alloys. ISBN 978-0-08-045370-5. Crossref

\section{Online sources}

https://chemistry.stackexchange.com/questions/111790/eutectic-phase-diagram-of-al-si-analysis

https://www.chemistrylearner.com/aluminum-nitride.html

Ionitech Ltd.,202. Retrieved from https://www.ionitech.com/services.html

https://www.open.edu/openlearn/science-maths-technology/engineeringtechnology/manupedia/plasma-nitriding/carburising

Rossi P., 2015, Quantitative Classification and Assessment of Modification in Hypoeutectic Aluminum Silicon Alloys, Retrieved from URL https://scidok.sulb.unisaarland.de/bitstream/20.500.11880/23163/1/20151208_Thesis_Rossi.pdf

Stena Aluminium Ltd., 2019, Aluminium alloy EN AB-43400. Retrieved from URL https://www.stenaaluminium.com/

TU-Sofia, NIL Efttom, Bulgaria, 2021. Retrieved from URL http://www.efttom.com/text/?text_id=2 